Retraction

\title{
Retracted: Analysis of Pull-In Instability of Geometrically Nonlinear Microbeam Using Radial Basis Artificial Neural Network Based on Couple Stress Theory
}

\author{
Computational Intelligence and Neuroscience \\ Received 17 February 2018; Accepted 17 February 2018; Published 2 May 2018 \\ Copyright (c) 2018 Computational Intelligence and Neuroscience. This is an open access article distributed under the Creative \\ Commons Attribution License, which permits unrestricted use, distribution, and reproduction in any medium, provided the \\ original work is properly cited.
}

\begin{abstract}
Computational Intelligence and Neuroscience has retracted the article titled "Analysis of Pull-In Instability of Geometrically Nonlinear Microbeam Using Radial Basis Artificial Neural Network Based on Couple Stress Theory" [1]. The article was found to contain a substantial amount of material from the following published article: Mohammad Heidari, Yaghoub Tadi Beni, and Hadi Homaei, "Estimation of Static Pull-In Instability Voltage of Geometrically Nonlinear EulerBernoulli Microbeam Based on Modified Couple Stress Theory by Artificial Neural Network Model," Advances in Artificial Neural Systems, vol. 2013, Article ID 741896, 10 pages, 2013. doi:10.1155/2013/741896 [2]. In addition, Figures 17 and 18 in [1] are similar to Figures 9 and 11 in [2]. Dr. Mohammad Heidari did not agree with this retraction, while Drs. Ali Heidari and Hadi Homaei were not reachable.
\end{abstract}

\section{References}

[1] M. Heidari, A. Heidari, and H. Homaei, "Analysis of pull-in instability of geometrically nonlinear microbeam using radial basis artificial neural network based on couple stress theory," Computational Intelligence and Neuroscience, vol. 2014, Article ID 571632, 11 pages, 2014.

[2] M. Heidari, Y. Tadi Beni, and H. Homaei, "Estimation of Static Pull-In Instability Voltage of Geometrically Nonlinear EulerBernoulli Microbeam Based on Modified Couple Stress Theory by Artificial Neural Network Model," Advances in Artificial Neural Systems, vol. 2013, pp. 1-10, 2013. 